\title{
FERNANDO PAIXÃO
}
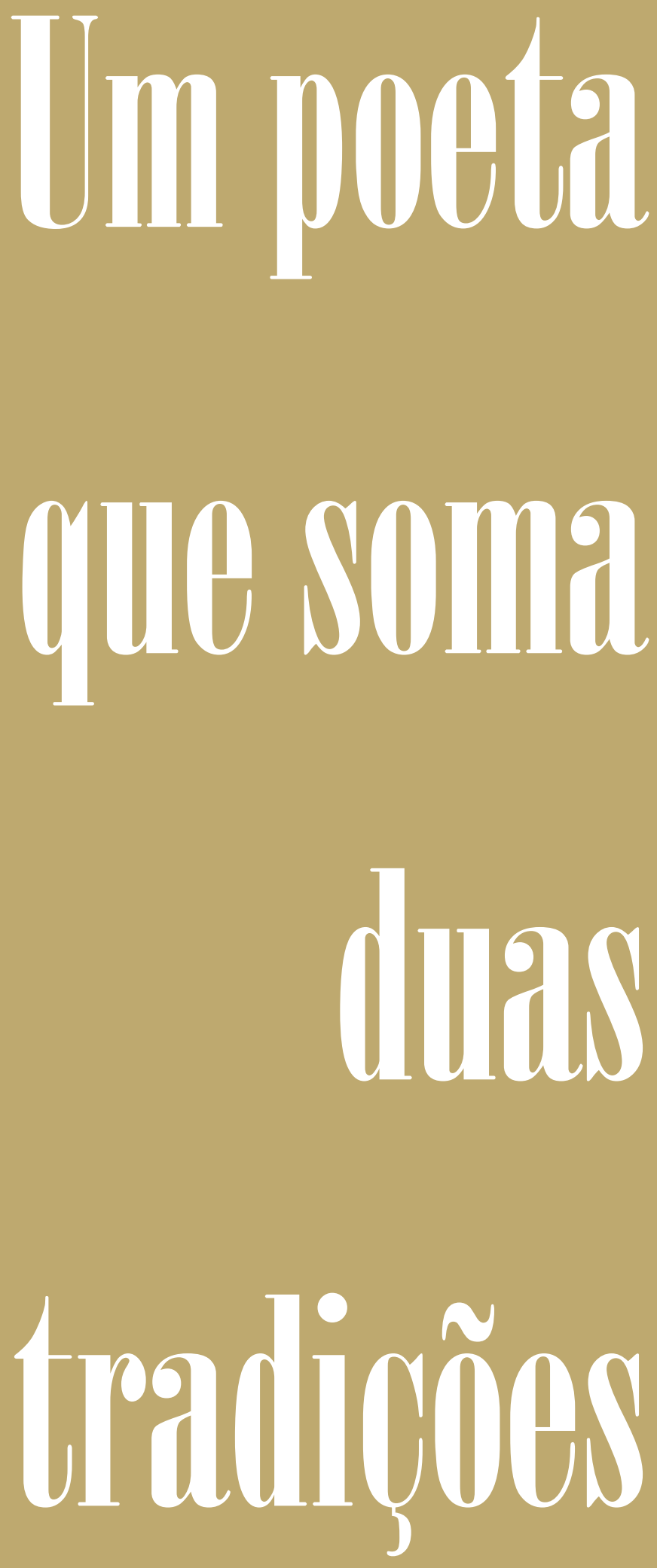


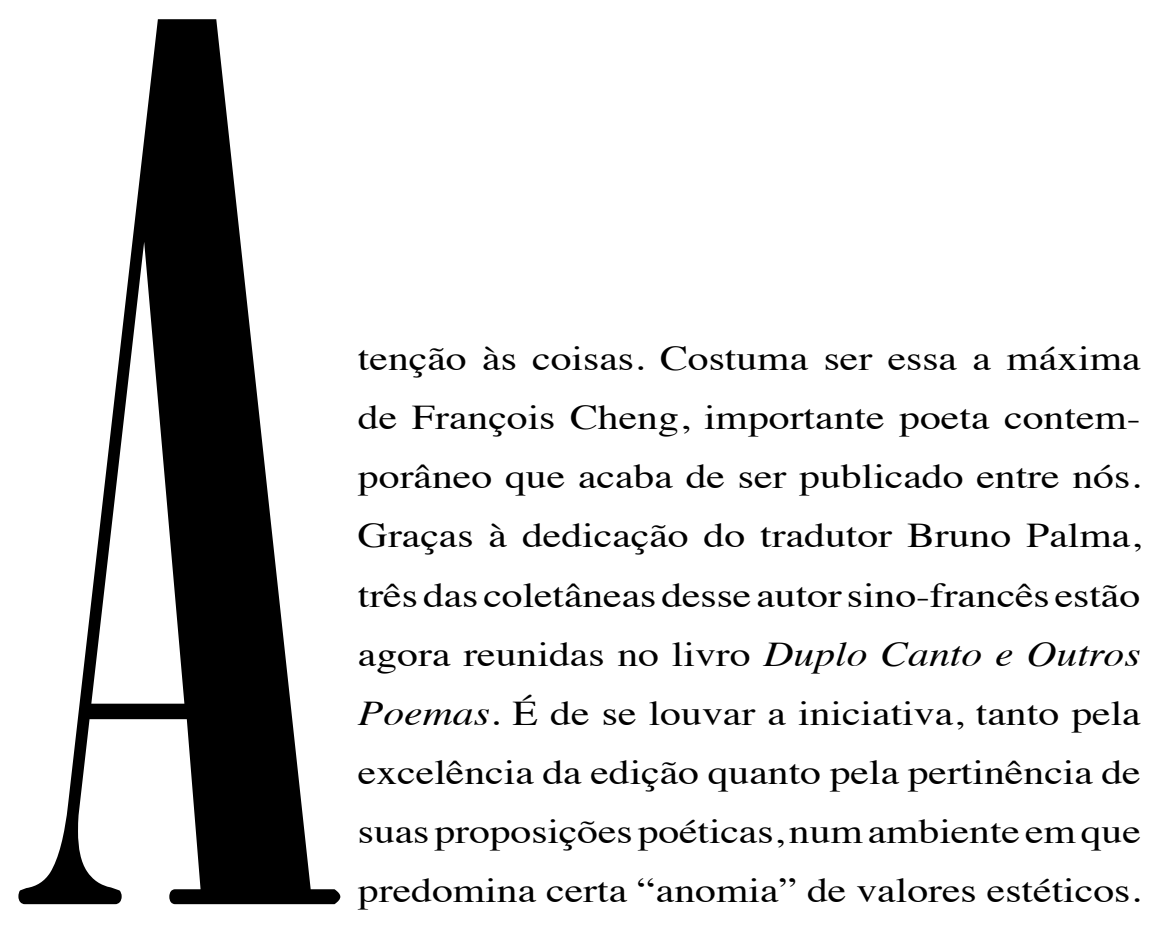

Cheng é dono de uma singular voz poética que alia as peculiaridades da lírica oriental - sobre a qual se tornou um especialista - a uma sensibilidade pessoal e cultivada, de quem cresceu em ambiente europeu; vivencia, portanto, uma situação de ponte entre as duas culturas. O reconhecimento de sua trajetória veio em 2002, ao ser eleito para a Academia Francesa, depois de uma carreira de acumulados méritos intelectuais.

Como ensaísta, escreveu diversos livros sobre arte e poética chinesa, mas também sobre temas relacionados à filosofia, como se deu em Cinco Meditações sobre a Beleza (2006), que teve amplo sucesso. Em paralelo, realizou a tradução de poetas franceses para a língua de seu país de origem, e vice-versa, além de ter publicado dois romances. O centro de sua obra, contudo, está em seus inúmeros livros de poesia, influenciada igualmente pelas duas margens de sua formação.

Poeta especial que é (até pelo fato de ter-se convertido ao catolicismo), Cheng aposta numa atenção sensível para com as coisas. Que coisas? Qualquer uma que se apresente aos olhos - um pássaro, um rosto ou um rio que corre - e traga consigo o estímulo de um pensamento encantado, imagem que puxa o fio de um verso e assim por diante. Muitos dos seus poemas recorrem a certos referenciais da realidade, mas para tirar deles um rol de metáforas que alarga o sentido de maneira delicada e por vezes inusitada.

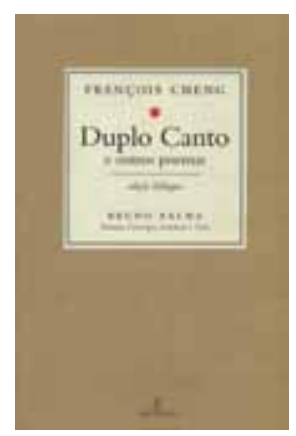

Duplo Canto e Outros Poemas, de François Cheng, Cotia, Ateliê, 2011, 448 p.

\section{FERNANDO PAIXÃO}

é escritor, professor de Literatura do Instituto de Estudos Brasileiros (IEB) da USP e autor de, entre outros, Poesia a Gente Inventa (Ática). 
É o que se encontra já no primeiro livro e que dá título à trilogia: Duplo Canto (2000).Foi consagrado com o Prêmio Roger Caillois e constitui uma perfeita iniciação à poética do autor. Em torno às imagens matrizes da Pedra e da Árvore transcorre uma série de poemas em que se desdobram as associações e ensinamentos que o poeta recolhe, orientado por um princípio de "diálogo com os elementos".

A primeira parte - sob o título "Um Dia, as Pedras" - apresenta um rol de textos gerados pela ideia de rochedo, mas que na verdade acolhem imagens de tal ordem que a matéria inorgânica passa a espelhar as qualidades afetivas e oníricas que habitam a consciência humana. Dizendo de outro modo, as pedras tanto servem de espelho ao poeta quanto assumem o papel de contraponto e resistência, apresentando-se em modulações:

"Bloco intransigente

Mesmo reduzido a migalhas

Somos a vida inteira

Sob o ignóbil martelo

Cada estilha alcança todos os gritos

Cada lasca

Clama a inocência nua” (p. 79).

Há muito a se dizer e perceber, portanto, no espaço das pequenas coisas ou mesmo nos detalhes das que são grandes - onde afinal se escondem as epifanias dignas de serem cantadas. As pedras, por exemplo, nos ensinam a conviver com o silêncio, conduzem-nos a não se ter medo do cordão mudo que nos envolve: "Voa pro infinito aberto/ no interior de ti mesmo" (p. 93).

Já na parte seguinte - com o sugestivo título de "A Árvore em Nós Falou"-, transcorre um procedimento semelhante, resultando em uma verdadeira fenomenologia poética sobre a natureza cósmica da árvore. As imagens, marcadas pelo espírito de síntese, próprio da poesia oriental, configuram diversas circunstâncias e pensamentos que acabam por humanizar a matéria observada. Certos poemas emprestam voz ao pássaro e aos frutos, com o intuito de capturar toda a trama envolvida com aquela imagem-matriz.

Resulta, portanto, um conjunto em que o canto se realiza por via do minimalismo poético; poemas de poucos versos, mas que ao mesmo tempo valorizam cada uma das pausas e espacializações, além de reforçar a cadência e contraste entre vogais e consoantes. Quanto às imagens, evocam quase sempre o meio da natureza, em suas múltiplas e contraditórias aparições. Em simultâneo, registram um olhar humano - afeito a sensações - e identificado com aqueles elementos. Cada poema se oferece como fruto de uma profunda meditação.

Por outro lado, a articulação entre as peças acaba por criar uma atmosfera comum aos textos. Pode-se mesmodizer que o poeta dança com os elementos naturais. Capaz de dar dobras aos pensamentos e ainda assim preservar o sentido de uma unidade maior: "Rochedo propulsando árvore/ Árvore aspirando rochedo//Círculo assentado reatando/ A aliança entre terra e céu" (p. 53).

Não é muito diferente a experiência fixada no livro seguinte: Cantos Toscanos ${ }^{1}$ (1999). Expressa desde o título o tom e o locus inspirador dessa sequência de poemas altamente tocantes e em diálogo fecundo com a Itália e sua riqueza humana e cultural, da qual Cheng se tornou admirador. Ao mesmo tempo, essa obra se propõe a tomar a terra como elemento gerador de imagens, entendida como um espaço de coabitação entre impulsos diversos. Da terra se produzem as ruínas e os jardins.

Deparamos então com uma série de textos curtos formados todos por uma estrofe de seis versos, complementada por uma linha final, em separado. A regularidade formal, contudo, não altera o propósito e o efeito de encantamento, flagrado por um olhar que observa e descobre, que se espanta e se enternece.É quando a observação do espaço ganha em qualidade afetiva e consegue se formular em figuras:

\footnotetext{
"A redondez da colina

- um instante de repouso dos remoinhos telúricos -
} 
Eis o outeiro do Desejo,

Que os raios do sol poente

Afloram, logo mudados

No longo pesar da bruma”.

É curioso observar como a paisagem campestre ressoa imagens consoantes a um círculo de subjetividade que se explicita a partir de fora, de maneira indireta. Por meio do uso rigoroso das metáforas, o poeta em verdade acaba por flagrar a simbiose entre o que está dentro e fora, no alto e no baixo, no objetivo e no subjetivo. Por força e agudeza do olhar, os antagonismos se entregam a um mesmo fluxo.

Ao seu modo, Cheng realiza com a sua poesia aquilo que constatou na pintura chinesa antiga. Ao escrever a respeito, ele a define como concebida essencialmente a partir da exploração das dicotomias visuais: vazio/cheio, alto/baixo, claro/escuro, forte/fraco, etc., mas com a expectativa de, no entremeio das forças, estabelecer-se o chamado Sopro ${ }^{2}$, valorizando os tons intermediários e os detalhes de luz.

O Sopro, segundo essa concepção, manifesta-se por meio da singularidade do Traço, conduzido pela mão a capturar um registro único e múltiplo. Diz Cheng: "[O traço] contém o ritmo e as pulsões secretas do homem" (p. 64). Pois bem, transpostos da pintura para a poesia, tais conceitos permanecem válidos e servem mesmo de chave de leitura. Nos versos de Cheng, o Sopro transparece no ritmo das frases e o Traço mostra-se configurado na imagem que dele resulta.

Exemplo disso encontra-se no modo como os versos desse livro se apropriam do espaço ou a ele se referem - com leveza e tato, de maneira cortante ou impiedosa. A dimensão espacial funciona como se fosse uma tela em que se inscrevem os pensamentos e as imagens do poeta. De um lado, acenam com a atmosfera da Toscana e seus ares tão marcados pela presença/ausência de luz. Aura do lugar. E, de outro, a visão subjetiva daquele que articula uma percepção atenta às coisas presentes.

Em sentido amplo, as imagens de Cheng
- sobretudo nesses dois livros iniciais - desenvolvem uma poética do olhar. Continuamente o poeta se interroga sobre o espaço e a resultante de sua afinidade com aquilo: “O infinito não é/ Senão o vai-e-vem/ entre o que se oferece/ E o que a si se procura" (p. 293). Tem ele consciência, pois, que mesmo uma paisagem está ali para ser preenchida por conteúdos humanos.

Já o livro último da trilogia traduzida volta-se para um tema a um só tempo complementar e diferente: Ao Longo dum Amor (2003). Pois também no movimento amoroso ocorre de haver o postulado de quem sente e se relaciona com o outro - as coisas em segundo plano. Diálogo ainda mais sinuoso e pleno de sentidos, portanto, que a sensibilidade de Cheng leva ao ponto máximo do lirismo.

Entra em jogo uma dualidade de margens que desejam misturar as suas águas - mas nem sempre obtendo sucesso na empreitada. O amor, afinal, está sempre na corda bamba: "Perto demais/ arde a chama// Longe demais/ foge a nuvem". Sobressai, contudo, a carga simbólica comum aos dois seres. Enredados no encanto mútuo, todos os gestos ganham ressonância e significação.

Deparamos, então, como universo de 46 poemas em formatos múltiplos eque pontuam flagrantes do relacionamento, entendido sob a ótica de uma espiritualidade comum. A percepção amorosa resulta não de um estado pleno de sentimento, perdurável no tempo, mas sim de uma atenção minuciosa aos pequenos gestos e sinais. Ao modo de um sopro, o amor deixa traços de passagem a serem interpretados.

Por conta disso, esse livro se diferencia dos anteriores por investir principalmente num contraponto afetivo a ser desfrutado e decifrado:

"Somos clausura e finitude

Contudo é entre nós

Que sem fim brotará

O que a vida deseja

de mais vasto

de mais alto

de indefinidamente transmutável
2 "A falta de sopro é a definição por excelência da pintura medíocre. A noção de Yin-Yang é correlativa à do sopro, e encarna as leis dinâmicas que regem todas as coisas". Ver o ensaio "E Vacio y La Plenitud", in Revista El Passeante, Madrid, Siruela Editora, número duplo 20-22, 1993,pp.63-79. Referência do texto origina: Vide e Plein: Le Language Pictural Chinois, Editions Du Seuil, 1991. 
Amar é estar

adiante de si

Amar é dizer

‘Tu não morrerás’” (p. 367).

Dessa maneira, a comunhão amorosa enlaça os amantes e multiplica suas possibilidades, a ponto de atrair duas pessoas para uma terceira margem - desconhecida e misteriosa. A finitude do mundo, da qual não conseguimos escapar, acena para as coisas presentes, precárias, mas ao mesmo tempo abre horizonte para o desejo maior e transcendente.

François Cheng sabe disso e consegue realizar poemas que relevam algum detalhe ou percepção e deles extrai um sentido profundo a ser compartilhado. Instigado pelo visível, o poeta indaga-se pelo que está sugerido e oculto. Sem bem saber como, ama e é amado. Vive em estado de suspensão da identidade conhecida. Ao longo de um amor, os seres afinal se depurame se transformam. Renovam as energias e as vontades.

Curiosamente, nesse livro transparece a dupla identidade do poeta. Soma de suas águas. De um lado, a concisão e a assertividade de poemas que lembram a formação oriental do autor; de outro, nota-se um imaginário associado ao estado amoroso que revela clara influência da cultura de raiz cristã. Isso está presente, por exemplo,numa reiterada ideia de amor como sentimento ligado ao conceito de absoluto.

Boa parte dos poemas volta-se para registrar epifanias, desconsolos ou enigmas, cuja medida ideal está dada pela completa (e impossível) integração (e supressão) das individualidades. É de se notar ainda que o poeta, ao tratar do amor, não aceite a precariedade e provisoriedade - ao contrário do que nos faz ver e aceitar quando trata dos elementos naturais.

Depois de maturação longa, o sentimento amoroso resulta em simbiose final, registrada no último texto: "Se o quer teu sopro/ seremos canto/ Raízes enleadas/ ramos enlaçados/ Todas as vozes única via/ Todos os ecos única vaga". Ao flagrar o movimento amoroso associado a um jogo entre o absoluto e a queda, não deixa de haver aí também um retorno às noções correlatas de vazio/pleno, claro/escuro, etc.

Cabe aoolhar humano escolher caminho entre as dualidades... Lição que sintetiza a leitura dos três livros, aqui comentados.

Portanto, em Duplo Canto e Outros Poemas, deparamos com uma poética diferenciada-seja pelo viés orientalista de suas imagens, seja por conta da escrita voltada para os valores essenciais. Os poemas aqui reunidos transmitem uma voz posicionada, forjada no interior de uma visão de mundo que, antes de se transformar em verso, passa por recolhimento e meditação. Traz à tona apenas os dizeres que o tempo deixa sedimentado. Em perfeita coerência com a trajetória de seu autor, aliás.

François Cheng forjou ao longo de sua vida uma carreira intelectual coerente e marcada pela procura de contínuo aprimoramento pessoal e estético. Teve uma existência, aliás, plena de desafios. Superou as dificuldades de imigrante sem dinheiro quando chegou a Paris em 1948, declinou do desejo de voltar ao seu país de origem por conta da perseguição aos intelectuais promovida pela Revolução Cultural.Enfrentou inúmeras adversidades, mas conseguiu dedicar-se aos estudos na Sorbonne, defendeu tese de doutorado, elogiada por Barthes e Lacan, converteu-se ao catolicismo e retornou à China 33 anos depois de sua partida.

Hoje é um escritor reconhecido por sua contribuição ao diálogo de culturas tão diferentes e por ser criador de uma lírica de alta originalidade. Sua poética aposta na contramão do experimentalismo ou do nonsense, tão disseminados em nossa época, e promove uma revisitação aos modelos da tradição, mas transmudados para uma sensibilidade que vive em nossos dias. Em comum com os poetas da Antiguidade, a observação atenta da natureza em suas múltiplas manifestações e metáforas.

Uma vez mais, a atenção às coisas Pedras, árvores, terras da Toscana... E a convivência com a amada.

Para que a poesia de François Cheng aconteça sob os olhos do leitor, pura como a água. 